\title{
Escrita e autoria em texto de iniciação científica no ensino fundamental: uma outra relação com o saber é possível?
}

\author{
Writing and authorship in scientific initiation text \\ in elementary education: is it possible to have another \\ relationship with knowledge?
}

José Carlos da Silveira ${ }^{1}$. Suzani Cassiani ${ }^{1}$. Irlan Von Linsingen ${ }^{1}$

\begin{abstract}
Resumo: Este artigo reúne reflexões em torno do trabalho interdisciplinar, articulado em uma prática pedagógica de Iniciação Científica no âmbito do Ensino Fundamental. Ao assumir a escola como espaço de construção de conhecimento, professores e estudantes podem atribuir outros sentidos à instituição escolar, ressignificando aí seus próprios lugares. Reforçado com o advento da internet, o ato de copiar e colar tem contribuído para a formação de sujeitos, no dizer de Freire, mais espectadores do mundo do que recriadores. Assim, compreendemos a tarefa de pesquisar como atividade fundamental na formação do estudante crítico, reflexivo, criativo: sujeito-autor. Ao trabalharmos com referenciais teórico-metodológicos da Análise de Discurso de linha francesa e a perspectiva crítica da educação em Ciência, Tecnologia e Sociedade (CTS), procuramos refletir sobre outra possibilidade de relação entre escola/estudante/professor/saber, que aponte para uma maior identificação da escola com a formação científica emancipatória.
\end{abstract}

Palavras-chave: Iniciação científica. Ensino fundamental. Interdisciplinaridade. Ciência, tecnologia e sociedade.

\begin{abstract}
This article gathers thoughts about interdisciplinary work, connected in a pedagogical practice of scientific initiation on the elementary school area. Acknowledging the school as a learning construction space, teachers and students can assign other senses for the schooling institution, giving a new meaning to their own places. Reinforced with internet's advent, the act of copy and paste has contributed for the formation of subjects, in the words of Freire, more like spectators of the world than recreators. Thus, we grasp the task of searching as a fundamental activity on the formation of the critic, reflexive, creative student: subject-author. By working with theoretical and methodological approach of the French Discourse Analysis and the critic perspective of Science, Technology and Society Education, we seek reflections about another possibility of relationship between school/student/teacher/knowledge, that points towards a bigger school's identification with the emancipatory scientific formation.
\end{abstract}

Keywords: Scientific initiation. Elementary school. Interdisciplinary. Science, technology and society.

\footnotetext{
${ }^{1}$ Universidade Federal de Santa Catarina (UFSC), Programa de Pós-Graduação em Educação Científica e Tecnológica (PPGECT), Florianópolis, SC, Brasil. E-mail: <jc.silveira@ufsc.br>.
} 


\section{Introdução}

Será o ato de conhecer aquele através do qual um sujeito, transformado em objeto, recebe pacientemente um conteúdo de outro? (FREIRE, 1977, p. 26).

Ao problematizar aspectos em torno das relações em que a escola na Educação Básica estabelece com o conhecimento, este texto tem como objetivo refletir sobre o papel da Iniciação Científica no estímulo ao exercício da autoria no cotidiano escolar de estudantes do Ensino Fundamental.

O sentido para Iniciação Científica que apontamos, a nosso ver, não caminha na mesma direção do que se apresenta no sentido dominante. A prática de Iniciação Científica, em sentido amplo, tal qual conhecemos hoje em nosso país, foi instituída em $1951 \mathrm{com}$ a criação do Conselho Nacional de Desenvolvimento Científico e Tecnológico (CNPq), uma agência de fomento muito respeitada no Brasil. De acordo com esse órgão, cabe à Iniciação Científica (IC) a função de despertar "vocação científica e incentivar talentos potenciais entre estudantes de graduação universitária, mediante participação em projeto de pesquisa, orientados por pesquisador qualificado" (CONSELHO NACIONAL DE DESENVOLVIMENTO CIENTÍFICO E TECNOLÓGICO, 2006).

O ano de 1986 marca a institucionalização da primeira experiência sistematizada de Iniciação Científica voltada aos estudantes de Ensino Médio, estruturada pelo Programa de Vocação Científica (PROVOC), da Fundação Oswaldo Cruz (FIOCRUZ). Em 2003, em grande medida inspirado no PROVOC, o CNPq criou seu próprio programa denominado de Iniciação Científica Júnior, voltado então aos discentes do Ensino Médio das redes públicas de ensino. A partir de 2008, o referido programa contemplou também os estudantes do $6 .^{\circ}$ ao 9. ${ }^{\circ}$ anos do Ensino Fundamental (CONSELHO NACIONAL DE DESENVOLVIMENTO CIENTÍFICO E TECNOLÓGICO, 2008 ). Nos citados formatos de IC, a responsabilidade no encaminhamento do Programa se deu em parceria com as Fundações de Apoio à Pesquisa (FAPs), existentes nos Estados da federação. Outra ação de ampliação da IC ocorreu com a criação, em 2010, do Programa Institucional de Bolsa de Iniciação Científica (PIBIC-EM), uma modalidade de IC Júnior voltada então para o Ensino Médio e articulada com o envolvimento de Instituições de Ensino Superior (IES). No entanto, embora o inegável movimento de ampliação da IC para as escolas públicas, há indícios de que seus objetivos e a dinâmica metodológica não foram devidamente considerados nos diferentes formatos apresentados.

Nesse movimento histórico envolvendo a inserção da Iniciação Científica na Educação Básica, como experiência local, sinalizamos o desenvolvimento de uma proposta articulada no Colégio de Aplicação da Universidade Federal de Santa Catarina. Designada por "Pés na Estrada do Conhecimento - Iniciação Científica na Escola", foi delineada para o 9. ano do Ensino Fundamental e está em vigência desde 1999. Diferentemente dos encaminhamentos governamentais citados, está estruturada organicamente à dinâmica curricular da escola. Queremos dizer que seu existir pedagógico não está condicionado a processos seletivos, como em geral acontece nos programas oficiais, e que o encaminhamento de orientação dos estudantes pesquisadores se dá pelo próprio corpo docente da instituição escolar, afinado com os interesses formativos próprios desse nível de ensino. 
Pelo exposto, ao problematizarmos a escola enquanto lugar de exercício de autoria, em dado contexto de Iniciação Científica, consideramos os estudantes sujeitos sócio-históricos que possuem e constroem histórias e sentidos sobre o mundo em que vivem (CHARLOT, 2000; ORLANDI, 2005). Nessa direção, a escola, por meio de seus sujeitos, ao propor uma formação problematizadora do mundo, deve superar objetivos que envolvam meritocracia ${ }^{2}$ e processos excludentes, como um Ensino de Ciências que intente exclusivamente formar cientistas. Assim, uma formação pelo viés de uma Iniciação Científica, nos moldes que estamos refletindo, não deveria se voltar apenas a determinados estudantes, reconhecidos como “jovens talentos”, com visível potencial cognitivo, mas se constituir democraticamente como oportunidade para todos.

Dessa forma, para darmos encaminhamento às discussões a que nos propusemos, partimos da pergunta: como o trabalho com a autoria em funcionamento, em uma dada proposta de Iniciação Científica, pode contribuir para a possibilidade de produção de outra relação com o saber? Para tanto, tendo como discussão central o exercício da autoria no Ensino Fundamental, apresentamos como corpus de análise dois textos produzidos coletivamente por três estudantes de $9 .^{\circ}$ ano. Os referidos materiais simbólicos - um "projeto de pesquisa" e um "ensaio escolar" - foram analisados à luz do referencial teórico da Análise de Discurso (AD) de linha francesa (ORLANDI, 2005; PÊCHEUX, 1988), e da perspectiva crítica de educação CTS (AVELLANEDA; LINSINGEN, 2014; LINSINGEN, 2007; LINSINGEN; CASSIANI, 2010).

\section{Sociedade, linguagem, ciência, tecnologia: possíveis articulações pedagógicas em contextos escolares}

Ao propormos uma discussão acerca dos alcances pedagógicos da Iniciação Científica no Ensino Fundamental, evidenciamos discussões que envolvem o conhecimento científico como possibilidade de emancipação social. Nessa perspectiva, destacamos a reflexão de Linsingen (2007, p. 13) ao afirmar que a educação crítica de enfoque CTS visa à "formação de indivíduos com a perspectiva de se tornarem cônscios de seus papéis como participantes ativos da transformação da sociedade em que vivem". Pensamos que uma educação que se pretenda crítica deva estar comprometida com a construção de uma sociedade solidária, equitativa e ética capaz de atuar com alteridade. Discutir ciência, nessa perspectiva, implica ressignificar a escola e seu projeto de construção de sujeitos e sociedades. No dizer de Santos (1998, p. 26),

[...] a educação não tem como objeto real armar o cidadão para uma guerra, a da competição com os demais. Sua finalidade, cada vez menos buscada e menos atingida, é a de formar gente capaz de se situar corretamente no mundo e de influir para que se aperfeiçoe a sociedade humana como um todo. A educação feita mercadoria reproduz e amplia as desigualdades,

\footnotetext{
${ }^{2}$ A expressão meritocracia que nos referimos remonta a Michel Young que, em 1958, cunhou o neologismo "meritocracia" (governo do mérito) em seu livro The rise of meritocracy, descrevendo uma sociedade, no caso a britânica, na qual o ideal do mérito justifica novos padrões de exclusão social e de desigualdade (KREIMER, 2000, p. 12).
} 
sem extirpar as mazelas da ignorância. Educação apenas para a produção setorial, educação apenas profissional, educação apenas consumista, cria, afinal, gente deseducada para a vida.

Desde os anos 1950, no contexto político, econômico e social pós-Segunda Guerra Mundial, em países industrializados do polo dominante do padrão de poder mundial (PORTO-GONÇALVES, 2015), como os Estados Unidos, a perspectiva CTS esteve voltada, sob o ponto de vista curricular, às Ciências da Natureza. Em tal conjuntura, as preocupações estavam fundamentalmente relacionadas a temas científico-tecnológicos, com a intenção de formar cientistas e tecnólogos para alavancar a economia e dar conta das relações de poder no contexto econômico, político, militar e ideológico da Guerra Fria.

A partir do final dos anos 1960, e durante a década de 1970, o pensamento CTS foi assumindo novos contornos e discussões, conquistando espaços no polo dominado do referido padrão de poder mundial, como o latino-americano. A ampliação do debate até o tempo presente vem criando condições para a produção de outros sentidos em torno da educação CTS (LINSINGEN; CASSIANI, 2010). Dessa forma, se em um primeiro momento, como já dissemos, houve uma maior aproximação da perspectiva citada às ciências da natureza, na atualidade, vê-se outro movimento de articulação entre educação e concepção de ciência e tecnologia que supera a dimensão disciplinar "procurando problematizar as relações de ordem social, cultural e política que se configuram em uma sociedade e situação localizadas" (AVELLANEDA; LINSINGEN, 2014, p. 517).

No entanto, tomando como referência a Educação Básica, evidenciamos não ser comum a circulação de propostas curriculares alicerçadas em perspectivas que promovam articulações entre áreas do conhecimento como ciências humanas, ciências da natureza e linguagens. Tal situação, de certo modo, evidencia ainda a primazia de uma formação muito mais atrelada às disciplinas denominadas "científicas" provenientes das ciências da natureza.

Entendemos que possíveis abordagens oriundas das áreas de humanas e linguagens, no trato de temas que envolvam sociedade e suas relações com ciência e tecnologia na perspectiva apontada, tanto podem convergir com aqueles trabalhados pelas ciências naturais, como apontar para outras direções. Preocupações de ordem ética, econômica, política, cultural, aludidas pelo enfoque crítico CTS, constituem fecundo campo de aproximação entre as diversas áreas do conhecimento.

A escola, lugar de construção do conhecimento, constitui um espaço privilegiado de possibilidades e aproximações das diferentes experiências do viver humano: da ética, da estética, da ciência, da tecnologia, da cultura, dentre outras. Nessa perspectiva, como situar o sujeito estudante, em geral quase sempre visto como receptor de conhecimento? Acreditamos que esse lugar social necessita ser ressignificado, não apenas por ações externas à escola, como também, e principalmente, em seu interior. Do período feudal, onde a educação esteve fortemente ligada à religião e à formação de elites econômicas e políticas, passando pela institucionalização da educação pública conformada pelo capitalismo nascente, até nossos dias, a forma da instituição "escola" passou por muitas alterações (mobiliários, material didático, espaço físico, tecnológicas), mas sua essência ainda guarda muito de sua origem. Na contramão dessa construção, floresce nas escolas a propagação de discursos pedagógicos emancipatórios, em profuso diálogo com a formação crítica, demarcando novos contornos ao espaço do aprender do/no tempo presente. 
Nesse sentido, torna-se pertinente e necessário problematizar outras relações dos estudantes e professores com o conhecimento, consigo próprios e com o entorno local, regional e global. Se considerarmos as mudanças tecnológicas que ampliaram o acesso à informação, característica do meio técnico-científico-informacional (SANTOS, 1996), não se verificaram transformações significativas nas relações escola-estudante-professor-tecnologia-saber. Copiar/ colar informações, rapidamente realizados pelos comandos de "Ctrl-c" e "Ctrl-v", constituem para muitos professores e estudantes sinônimo de pesquisa. Tal situação abriu espaço nas instituições escolares para a ampliação exacerbada do plágio, muitas vezes com inconsistências e contradições que indicam uma incapacidade de análise crítica do que se faz. Certamente, não é tal prática que almejamos com nossas ações pedagógicas. Sobretudo, buscamos a responsabilidade no compromisso com a leitura e a escrita. Em relação ao plágio, segundo Orlandi (2012), o plagiador silencia a autoria, atuando como censor.

Tal situação, no que tange ao funcionamento da linguagem, reforça o quanto a instituição escolar, em geral, dá espaço para a repetição mnemônica, ou seja, à cópia, que não proporciona "rupturas de processos de significação" (ORLANDI, 2005, p. 36). Não queremos dizer que a repetição proporcionada pelo processo parafrástico não seja importante no processo de funcionamento da linguagem e na aprendizagem pela memória (VYGOTSKY, 1988). Sabemos que é por ela que novos sentidos podem ser atribuídos (polissemia), já que é no movimento/ tensão entre paráfrase e polissemia que a própria linguagem se constitui (ORLANDI, 2005). Sublinhamos, com a referida autora, ser ilusão considerar o sujeito a fonte do dizer, pois sempre existe um retomar do que já foi dito. A nosso juízo, a busca incessante da escola deveria ser mais pela repetição histórica, pois ela considera a incompletude da linguagem (o lugar do possível), o deslocamento de sentidos, o equívoco e a falha os instrumentos que abrem portas para a possibilidade de outras interpretações. É nesse movimento histórico que dá ênfase aos modos como os sentidos são produzidos e circulam que vemos se constituir o sujeito-autor.

Assim, uma abordagem CTS em perspectiva discursiva, ao compreender o discurso enquanto palavra em movimento, articula aspectos relativos à linguagem possibilitando, dessa forma, "a construção de novos sentidos sobre a ciência e a tecnologia, que podem implicar mudanças significativas na educação, em geral, e na educação científica e tecnológica em particular" (LINSINGEN; CASSIANI, 2010, p. 169). Sob esse aspecto, ponderamos que, no processo educativo, considerar a não transparência da linguagem possibilita o movimento de outros processos de interpretação, desnaturalizando saberes cristalizados acerca, por exemplo, da neutralidade da ciência e da tecnologia, produtoras de silêncios sobre/nas práticas educativas em contextos escolares.

Dessa forma, tomando o texto escrito como objeto simbólico, passamos a analisar a produção de um ensaio escolar ${ }^{3}$ construído coletivamente por três estudantes de $9 .^{\circ}$ ano da

\footnotetext{
3 “O ensaio é um texto que expõe idéias, se dedica à reflexão crítica, mas ao mesmo tempo compartilha com a arte da possibilidade autonomia estética. Ele assume a forma livre sem um estilo definido. Sua natureza supõe diálogo, sua escritura supõe leitura. Ensaios são simples opiniões, são tentativas de escritas. A cordialidade, a abertura, a polêmica são marcas da escritura ensaística. Consiste na defesa de um ponto de vista pessoal e subjetivo sobre um tema (humanístico, filosófico, político, social, cultural, moral, comportamental, literário, etc.), com um objetivo de apresentar e defender uma idéia." (TROTT, 2008).
} 
instituição supracitada. Para fins de análise, utilizaremos a expressão "pesquisadores", ou "estudantes pesquisadores", quando nos referirmos aos estudantes, e "orientador", ou "professor orientador", para o professor responsável pelos encaminhamentos de orientação. Embora haja a presença do professor orientador, ele não é agente único desse processo. Por se tratar de uma perspectiva interdisciplinar de IC, a todo instante, outros saberes são acessados diante dos encaminhamentos dados pelo coletivo docente na dinâmica da proposta.

\section{Um texto em funcionamento: as condições de produção da escrita}

Para um melhor entendimento sobre os sentidos produzidos no corpus em análise, procura-se, em um primeiro momento, explicar as condições em que o material simbólico foi produzido, ou seja, apreender os sujeitos e a situação. O conhecimento dessas condições, segundo Orlandi $(2005,2012)$, possibilita compreender por que determinados dizeres são ditos de uma forma e não de outra.

O texto produzido pelos pesquisadores e seu orientador, um ensaio escolar intitulado "Mudança para nova cidade: comparando as percepções da Casa de Memória Camarolli e a dos moradores de Itá", resulta das atividades da primeira fase de IC ocorridas em 2012, na citada instituição. No referido ano letivo, os 75 estudantes que compunham os $9 .^{\circ s}$ anos foram organizados por meio de sorteio, em seis grupos, contando cada um com 12 a 13 integrantes ${ }^{4}$. Uma vez nos grupos, os estudantes se organizaram em equipes de três ou quatro componentes. Assim, foi apresentada aos pesquisadores a temática que estimularia a construção de suas propostas de pesquisa. Nessa fase, as discussões transitaram em torno da problemática do acesso à terra em nosso país, com ênfase no caso das populações atingidas por barragens. Conforme o trabalho proposto, a temática geral explorada por diferentes vieses (Quadro 1) possibilitou aos estudantes maior liberdade na escolha do enfoque de interesse.

Quadro 1. Eixos de discussão

\begin{tabular}{|l|l|}
\hline Eixo & \multicolumn{1}{c|}{ Discussão } \\
\hline 1 & Personagens e contexto: cotidiano, lideranças e estratégias de luta \\
\hline 2 & Luta pela terra: O Movimento dos Atingidos por Barragens - MAB \\
\hline 3 & $\begin{array}{l}\text { Natureza e Sociedade: problemas ambientais/sociais decorrentes da criação de } \\
\text { Usinas Hidrelétricas }\end{array}$ \\
\hline 4 & Luta pela terra e memória \\
\hline
\end{tabular}

Fonte: Universidade Federal de Santa Catarina (2012).

Ainda na fase de apresentação da concepção de IC, os estudantes foram orientados a construírem um pré-projeto de pesquisa ${ }^{5}$. As propostas criadas foram lidas, analisadas e distri-

\footnotetext{
${ }^{4}$ Como o número de orientadores sofre alterações de um ano para outro, a composição quantitativa dos grupos também se altera.

${ }^{5}$ Documento, numa versão inicial, contendo título, objetivo geral e objetivos específicos.
} 
buídas entre os seis professores das áreas de Ciências da Natureza (Ciências), Ciências Humanas (Geografia e História) e Linguagem (Língua Portuguesa e Arte Visual) que compunham a equipe dos docentes orientadores.

A indicação da temática e seus respectivos eixos estão inscritos em um contexto de preocupação dos professores em sensibilizar o grupo discente em torno de questões sociotécnicas e sua relação com, por exemplo, a organização de movimentos sociais, quase sempre desconhecidos e colocados à margem da dinâmica social. Ao proporem o debate em torno da construção de usinas hidrelétricas e os impactos naturais e sociais daí decorrentes, possibilitam que os estudantes pesquisadores compreendam os interesses político-econômicos envolvidos em questões de tal natureza, bem como a construção de processos sociais de participação pública e resistência contra-hegemônica.

Livros didáticos e/ou outros espaços de circulação de informações, tais como os midiáticos por exemplo, nem sempre se constituem suficientes para o debate crítico em sala de aula. Em geral, os conteúdos veiculados trazem discussões de forma breve, regionalizadas, muitas vezes descontextualizadas e/ou atravessadas por percepções problemáticas sobre temas polêmicos, como aqueles envolvendo questões étnico-raciais, de gênero, religiosos que inferiorizam sujeitos e seus saberes, reforçando assim ideologias dominantes (re)produtoras de situações de exclusão social.

O espaço de IC, dependendo de sua configuração, pode indicar possibilidades fecundas para o tratamento de temas sociotécnicos. Acreditamos ser papel da escola, como lugar de conhecimento, tratar de problematizar o que está cristalizado naquelas percepções, trazendo para o debate determinantes políticos, econômicos, culturais, constitutivos de tais temáticas. Assim, compartilhamos com Giraldi (2010) sua reflexão sobre a necessidade da construção, em contextos escolares, de espaços de dizer. Em diálogo com a autora, vê-se que a constituição de tais espaços reflete o caráter dinâmico das referidas instituições, plenas de possibilidades para a construção de outros olhares e interpretações sobre o mundo. Nesse sentido, de acordo com autora, “[...] para a assunção da autoria, é preciso que os processos de ensino/aprendizagem escolar permitam a abertura de um espaço de dizer [...]” (GIRALDI, 2010, p. 136).

Trazendo a discussão para o que nos interessa neste artigo e deslocando sentidos em torno da noção "dizer", constatamos que a IC inaugura outros espaços de circulação da palavra, de diferentes gestos e emoções. Os sujeitos estudantes, na posição de pesquisadores, ao conhecerem outros lugares e seus espaços, como escolas, igrejas, sindicatos, empresas, praças, hidrelétricas, museus, dentre outros, estabelecem diálogos com seus interlocutores. Ao analisarem dados resultantes da investigação realizada, materializam na escrita seus achados e os tornam públicos, em eventos internos e externos à escola. Assim, vêm ampliando sua relação com a construção e circulação do conhecimento.

Retomando a discussão sobre a organização das equipes de pesquisa, após o momento preliminar de escolhas do que e como pesquisar, iniciaram-se os estudos para fortalecer a proposta investigativa. Nesse processo, pesquisadores e orientadores contaram com a colaboração de alguns profissionais (tanto da universidade, como fora dela) que tivessem interesses teóricos em torno das temáticas em questão. Além do contato com esses profissionais e/ou acadêmicos, os envolvidos com a proposta de IC assistiram ao filme "Narradores de Javé", uma produção cinematográfica nacional de 2003, escrita e dirigida por Eliane Caffé, e fizeram uma análise que coloca em pauta o debate da construção de uma usina hidrelétrica e, por conseguinte, o 
alagamento de uma pequena cidade do interior do Brasil. A exibição do vídeo e o consequente debate teve como objetivo estimular os estudantes a considerarem as várias possibilidades de pesquisa que a temática suscitava.

Nessa direção, no mês de maio de 2012, estudantes e orientadores participaram de um trabalho de campo por dois dias na cidade de Itá, localizada no Oeste de Santa Catarina (Figura 1). Lá conheceram a Usina Hidrelétrica Itá (UHE Itá), os espaços alagados da antiga cidade e o novo núcleo urbano construído. Antes da chegada ao destino programado, uma parada possibilitou a visita a um acampamento do MAB, organizado próximo ao canteiro de obras de uma barragem, na cidade de Abdon Batista. Em Itá, ao caminharem pelas ruas e praças, os estudantes entrevistaram moradores, representantes políticos da cidade e do referido movimento social. Visitaram uma escola pública municipal, onde conversaram com estudantes e professores sobre as razões de estarem visitando aquele espaço, convidando-os a colaborar com suas pesquisas. $\mathrm{O}$ trabalho de campo muitas vezes oportuniza momentos inusitados de geração de dados, nem sempre programados pelos pesquisadores. $\mathrm{Na}$ ocasião, estavam acontecendo na cidade as atividades da "Semana Nacional de Museus". Os estudantes participaram de uma "roda de conversa" que contou com a presença de pessoas que tinham nascido na cidade antiga e, portanto, tinham muitas histórias para serem contadas.

Figura 1. Localização geográfica de Itá

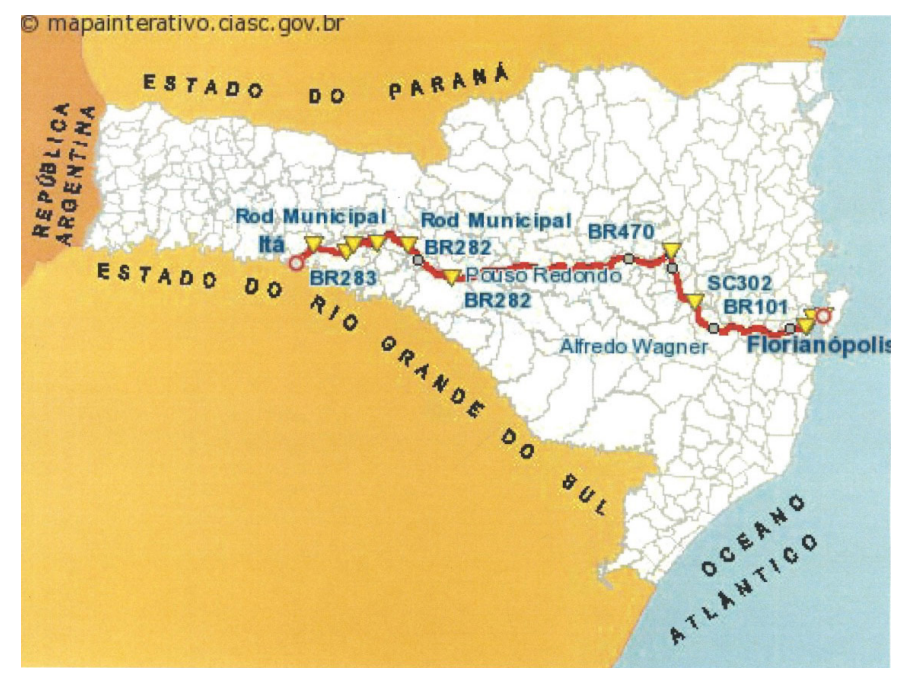

Fonte: Mapa interativo de Santa Catarina (2018).

Os estudantes pesquisadores, sujeitos desta reflexão, tinham idades entre 14 e 16 anos, sendo dois do gênero feminino e um do gênero masculino. O eixo escolhido por esse coletivo, conforme Quadro 1, foi o de número quatro "luta pela terra e memória", que abriu espaço para os estudantes discutirem questões relacionadas ao resgate histórico e cultural dos espaços atingidos, bem como sobre os impactos emocionais e culturais da transferência de uma cidade 
por ocasião da construção da UHE Itá. Além do professor orientador, essa equipe contou com o apoio de uma acadêmica do curso de Letras-Português ${ }^{6}$.

É importante considerar ainda, no que concerne às condições de produção, o processo de orientação aos estudantes. Sobre essa questão, o professor orientador relata que,

\begin{abstract}
A estratégia adotada para estimular o processo de construção do texto [a muitas mãos] foi pedir [e reafirmar muitas vezes] que eles tivessem em mente que estavam contanto algo a alguém, como em uma conversa. Para isso, eles precisavam ser minuciosos nos detalhes, precisavam inicialmente bem apresentar a temática, deveriam imaginar esse leitor como em um diálogo. Dessa maneira poderiam/deveriam entremear suas estratégias metodológicas com os resultados do trabalho [...]. Para a estruturação do texto, o caminho orientado foi o de que deveriam se utilizar dos diferentes objetivos especificos para definir as partes do desenvolvimento da escrita. Assim, cada um deles, por exemplo, poderia virar um subitem ou um subtitulo do trabalho final. ${ }^{7}$
\end{abstract}

O orientador da pesquisa relata que, no processo de construção do ensaio escolar, deparou-se com dificuldades dos estudantes relacionadas ao ato da escrita na perspectiva apontada. Ressalta, no entanto, que, embora apresentassem embaraços em interagir em sua redação com outros textos (intertexto), "conseguia perceber a significação desses textos para o amadurecimento, a articulação e o desenvolvimento das ideias no texto escrito" ". De acordo com o professor, a cada novo momento da escrita, eram trazidos à equipe questionamentos que tinham por objetivo gerar debate e avanço no processo de construção textual: "a ideia é que eles mesmos encontrassem e amadurecessem suas respostas através do debate em equipe quando, possivelmente, eram mobilizados seus conhecimentos sobre suas pesquisas" .

Ao pensar a relação com o saber em uma prática pedagógica de IC, vê-se o sujeito estudante no afã de aprender, em um contínuo compartilhar com os outros. Assim, a relação com o saber é relação com o mundo, consigo mesmo e com os outros (CHARLOT, 2000, p. 79). Para compreender a dinâmica desse sistema de relações e, nesse processo, compreender o movimento em direção a autoria, passamos a seguir à análise do material simbólico produzido pelos estudantes pesquisadores.

\footnotetext{
${ }^{6}$ Participações como essa constituem estratégias para possibilitar aos acadêmicos das licenciaturas outras formas de perceber as potencialidades pedagógicas do espaço escolar. Tal aproximação com as atividades de IC, tem sido um movimento constante dos professores responsáveis pelos estágios curriculares de Língua Portuguesa, Geografia e Ciências.

${ }^{7}$ Professor orientador. Entrevista concedida em 03/03/2013.

${ }^{8}$ Professor orientador. Entrevista concedida em 03/03/2013.

${ }^{9}$ Professor orientador. Entrevista concedida em 03/03/2013.
} 


\section{O movimento discursivo dos pesquisadores e a produção de sentidos no texto de Iniciação Científica}

O texto intitulado "Mudança para nova cidade: comparando as percepções da Casa de Memória Camarolli e a dos moradores de Itá", como já mencionamos, é uma produção coletiva realizada por três estudantes de Iniciação Científica do 9. ano de uma instituição da rede pública federal de ensino. Como já referido, os pesquisadores em questão optaram por caminhar pelo eixo quatro "luta pela terra e memória", que traz à tona questões relacionadas às memórias em torno da construção de uma barragem na cidade de Itá, localizada na microrregião do Alto Uruguai Catarinense.

No projeto de pesquisa construído pelos pesquisadores, identificamos os objetivos para o desenvolvimento da investigação. Como objetivo geral, propuseram comparar a visão que o museu passa para os visitantes com a visão que os moradores têm sobre o que vivenciaram à época do processo de construção da barragem e o consequente deslocamento populacional para a nova cidade. Definiram como objetivos específicos: "i - Perceber as diferenças de como é relatado por ambas as partes; ii - Analisar o que cada um utiliza para relatar o fato; iii - Acessar a memória do dia a dia entre os adultos e crianças na época; e, iv - Ampliar a visão de memória proposta pelo museu" (BUENO; RAMOS; SANTOS, 2012a, p. 4).

$\mathrm{Na}$ exposição dos objetivos, vê-se que o interesse demonstrado pela equipe foi o de compreender os dizeres sobre o processo de construção da barragem e a consequente transferência da população para a nova cidade, considerando dois interlocutores: o museu e a população que vivenciou essa história. Na perspectiva teórica que estamos trabalhando, é importante retomar que os dizeres não são apenas mensagens para serem decodificadas, sobretudo, efeitos de sentido. Dessa forma, a análise dos gestos de autoria dos pesquisadores se dará na relação que eles estabelecem em seus escritos com o que "foi dito"; o que "não foi dito", mas que significa; e o que "poderia ser dito". Nesse sentido, percebe-se o cuidado dos autores em dar voz à população atingida pela construção da barragem. A ênfase dada aos atores sociais atingidos produz deslocamentos sobre uma percepção tradicional envolvendo relações entre ciência, tecnologia e sociedade, que reforça a não participação dos sujeitos em assuntos que envolvam tais questões (LINSINGEN; CASSIANI, 2010).

$\mathrm{Na}$ introdução do projeto de pesquisa, estimulados pelas leituras e pelos debates com o professor orientador, os pesquisadores pressupuseram que "a população perdeu parte da sua identidade cultural, perdendo assim seus costumes, seus hábitos, seus rituais" (BUENO; RAMOS; SANTOS, 2012a, p. 3). Essa premissa apontada pela equipe foi o fio condutor da pesquisa na qual demonstraram o interesse em "investigar os sentimentos (as angústias, os medos, as perdas, as esperanças, entre outros) em torno da população nesse processo de deslocamento e mudanças na sua vida cotidiana" (BUENO; RAMOS; SANTOS, 2012a, p. 3).

Percebe-se o funcionamento de um mecanismo de antecipação na construção das premissas norteadoras da pesquisa. Apostam na ideia de que o museu, como espaço institucional, explicará o fenômeno da construção da barragem e da transferência populacional, silenciando os problemas enfrentados pela população. Tal situação é evidenciada no objetivo específico iv "ampliar a visão de memória proposta pelo museu", ou seja, identificaram que o museu abriga parte da memória, aquela vinculada aos interesses do empreendimento. Destarte, apontam para a necessidade da ampliação dessa memória a fim de dar vOz a outros dizeres sobre a realidade posta. Afinal, o que é o museu? Quem é a população atingida? 
O museu, denominado "Casa Camarolli" (Figura 2), é uma residência de descendentes de italianos que foi construída na década de 1940 por Felipe Camarolli e Guilherme Stentzler (BUENO; RAMOS; SANTOS, 2012b), no núcleo urbano original de Itá. Quando ocorreu o processo de conclusão das obras da barragem e a consequente transferência da população, essa casa foi desmontada e trazida para o novo núcleo urbano com o propósito de funcionar como uma Casa de Memória, em outras palavras, um museu. Esse espaço foi construído pelo consórcio de empresas Tractebel Energia, CSN e Itambé.

Figura 2. Casa de Memória

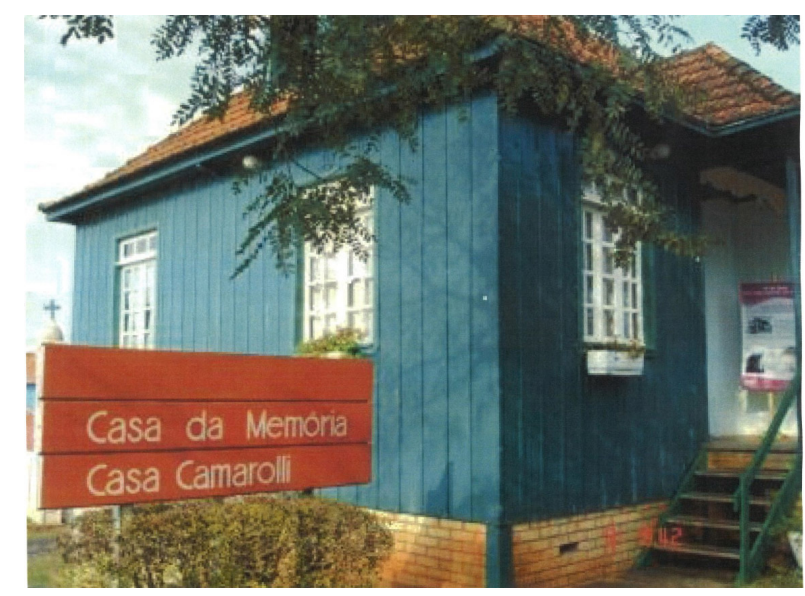

Fonte: Bueno, Ramos e Santos (2012b).

No que se refere à população, sujeitos da investigação realizada, a equipe de pesquisadores optou por trabalhar com a parcela populacional mais idosa. A opção por esse coletivo demográfico decorre dos propósitos da pesquisa, que pretendia trabalhar com memórias relativas a um período de tempo mais longo. Os estudantes pesquisadores, ao constatarem que a Casa Camarolli representava, de alguma forma, o poder instituído pelo consórcio responsável pela construção da UHE Itá, entenderam que o referido consórcio não teria “o interesse de preservar o lado ruim da transferência, o lado sentimental das pessoas ao deixarem a cidade, o lado das manifestações que aconteceram" (BUENO; RAMOS; SANTOS, 2012b, p. 4). Segundo o discurso dos estudantes, percebe-se o funcionamento do interdiscurso. Os “já ditos” nos encontros de orientação, nas leituras realizadas, bem como em outras experiências pessoais vivenciadas pelos estudantes, acessados pela memória discursiva, estavam significando ali, na reflexão proposta.

Se considerarmos as condições de produção em que as entrevistas se deram (BUENO; RAMOS; SANTOS, 2012a, p. 5), podemos compreender porque grande parte da população entrevistada avaliou a transferência para a nova cidade como algo positivo. Vejamos os relatos das entrevistas selecionados pelos autores:

Valeu, "pro" pessoal da cidade, valeu, sim [...]. [Paula] 
Eu acho que foi excelente, depois a gente acaba se acostumando com as coisas [...]. [Clarice].

A gente foi indenizada, foi tudo... eles pagaram bem [...] [Sônia]

[...] mas olha, tudo saiu ganhando, porque ninguém perdeu. [Antônia $]^{10}$

De acordo com as falas citadas, a transferência para a nova cidade parece não ter tido impactos negativos relevantes. As pessoas entrevistadas tinham forte relação com o meio urbano, já que residiram na cidade antiga quando crianças/jovens, ou a família (pai, mãe, avós) tinham tido tal vivência. Dessa forma, o deslocamento para um novo espaço urbano planejado pôs em funcionamento suas memórias discursivas de moradoras da cidade. Em outras palavras, algo que fala em outro tempo-espaço ecoa no presente, mitigando a existência de conflitos ou estranhamentos.

No entanto, se as entrevistas tivessem sido aplicadas para moradores rurais, certamente as respostas não teriam sido as mesmas, já que uma parcela significativa dessa população perdeu terras agricultáveis e não receberam a devida indenização. Muitas famílias foram enviadas para assentamentos agrícolas em diferentes regiões do Estado catarinense, sofrendo sérios processos de adaptação cultural, tendo, inclusive, que promover mudanças em suas práticas com o plantio e a criação de animais. Foram essas pessoas que, em geral, passaram a integrar movimentos sociais, como o MAB, com vistas à luta pelos direitos de acesso à terra. Há de se ressaltar que esta não era a proposta de análise da equipe, já que estavam realizando trabalho de campo no espaço urbano, e não teriam como aferir tal situação. Porém, de certa forma, a equipe não se posicionou sobre esta questão, já que nos seminários preparatórios, antes do trabalho de campo, esses aspectos foram intensamente trabalhados no coletivo. Nas sequências discursivas em destaque, em especial nos excertos "Valeu, 'pro' pessoal da cidade, valeu, sim [...]" e "Eu acho que foi excelente, depois a gente acaba se acostumado com as coisas [...]", a pesquisa realizada poderia ter explorado aspectos do intricado processo envolvendo decisão pública em assuntos de ciência e tecnologia. No caso em questão, sobre os impactos sociais de implantação de uma usina hidrelétrica nas condições estabelecidas pelo poder público (Estado) e privado (Consórcio).

Um subtítulo do texto denominado "O que o museu não diz: moradores discordam", já mostra outro movimento da equipe de pesquisa. Nesse caso, é possível relacionar situações, não apenas reproduzindo dizeres. Ao constatarem que os moradores, em geral, gostaram da transferência para o novo ambiente, destacaram que eles se assustaram com a possibilidade de terem que deixar seu espaço de moradia, o que gerou protestos em alguns casos. Tais situações, de acordo com os autores, não estão registradas na Casa de Memória:

[A] primeira [notícia] aqui na cidade foi um impacto muito grande pra nós, ficamos apavorados porque a notícia chegou de que [...] a nossa cidade ia simplesmente desaparecer [...]. [Paula]

\footnotetext{
${ }^{10}$ Os nomes dos sujeitos entrevistados são fictícios e as entrevistas foram concedidas aos pesquisadores na cidade de Itá (SC) em 18 de maio de 2012.
} 
[...] foi dolorido deixar a cidade, as casas tinham que se abandonar, tinha que sair porque não era mais meu, tinha que deixar porque era deles. Foi difícil. [Antônia]. (BUENO; RAMOS; SANTOS, 2012a, p. 5).

Ante a experiência da aplicação de entrevistas, enquanto recurso metodológico, os estudantes perceberam que a materialização de determinados dizeres só aconteceu em função do auxílio da memória de quem viveu aqueles tempos. Entenderam que essa situação não se aplicava ao coletivo como um todo, pois, como afirma Orlandi (2005, p. 82), "o que já foi dito, mas já foi esquecido, tem um efeito sobre o dizer que se atualiza em uma formulação. Em outras palavras, o interdiscurso determina o intradiscurso: o dizer (presentificado) se sustenta na memória (ausência) discursiva".

A Casa Camarolli, ambiente cultural municipal, organizado pelo consórcio empreendedor - ao autorizar a circulação de determinados dizeres e não de outros -, influencia o tempo presente dos habitantes e visitantes da cidade. Tais discursos, nessas condições, produzem efeitos de sentido sobre ciência e tecnologia aos que visitam o museu ao exaltarem apenas o desenvolvimento econômico regional e o bem-estar social produzidos. Os estudantes exercitaram importante olhar sobre a estratégia silenciadora da Casa Camarolli. Além das leituras e discussões sobre aspectos relacionados ao tema investigativo, tal percepção está ancorada no contato crítico com a realidade estudada, ou seja, o núcleo urbano e seus moradores, o museu, a hidrelétrica. No dizer dos autores, tal situação é assim expressa:

[...] podemos perceber que muitos elementos não são registrados pela Casa de Memória Camarolli, o que faz com que muitas destas coisas (manifestações, sentimentos de saudade, tristeza e depressão) não sejam lembradas, e com isso podem vir a cair no esquecimento da população. Podemos concluir com tudo isso que o consórcio de empresas (Tractebel Energia, CSN e Itambé) que criou e mantém o museu optou por mostrar somente alguns pontos positivos da história do município e do processo de transferência (BUENO; RAMOS; SANTOS, 2012a, p. 6).

Os pesquisadores, ao perceberem a estratégia de instalação de uma Casa de Memória no novo sítio urbano, ou seja, de mostrar somente alguns pontos positivos do processo de construção da usina e da transferência da população, conseguiram detectar uma forma de silêncio. Nesse sentido, pode-se dizer que a Casa de Memória, no que Orlandi (2005, p. 83) denomina de silêncio constitutivo, refere-se a tudo o que não foi dito para que outros dizeres pudessem ser enunciados. Observemos o discurso dos estudantes pesquisadores, quando tratam de aspectos relacionados à colonização de Itá:

Na visita a Casa de Memória, chamou-nos atenção o nome dado às salas do museu como, por exemplo, "Sala dos Pioneiros". Percebemos que a cultura indígena não foi mostrada pelo museu, dando assim a ideia de que a única cultura existente na época era a dos descendentes de italianos e alemães. Mas, antes de os teuto-brasileiros e os ítalo-brasileiros chegarem a Itá, já haviam indígenas das etnias Kaingang, Xokleng e Tupi-Guarani 
residindo na área do que hoje é aquele município. Isso não foi relatado, ou visualizado por nós na visita à Casa de Memória. (BUENO; RAMOS; SANTOS, 2012a, p. 3).

Em uma das entrevistas, concedida por um funcionário, os pesquisadores selecionaram um trecho que marca o silêncio que estamos pontuando. Essa busca dos estudantes se deu com a intenção discursiva de reforçar, para o leitor, a intencionalidade da existência daquela Casa de Memória.

[...] Houve alguns protestos, foram poucos. O pessoal resolveu não comentar muito [no museu] porque hoje em dia como tem muitas cidades aparecendo por causa da Usina, se deixasse, esses protestos [seriam tomados] como exemplo [...] o pessoal na época não segurou, não guardou alguns [documentos], não tinha muitos. Não tinha muita vontade de guardar, então não tinha o porquê. (BUENO; RAMOS; SANTOS, 2012a, p. 6). ${ }^{11}$

\section{A incompletude do texto: garantindo a continuidade da discussão}

Escrever, dizer, exercer autoria: ações do cotidiano escolar, seja no ambiente urbano ou rural, em uma sala de aula equipada com recursos tecnológicos de ponta ou em uma "sala" a céu aberto em um lugar qualquer. Usando o papel, a lousa digital, o chão ou somente a imaginação, tudo isso e muito mais são coisas da/na escola.

Propor Iniciação Científica na Educação Básica, sobretudo no Ensino Fundamental, constitui possibilidade de (re)ver a prática da escrita e da leitura em uma lógica que propicie a autoria, que estimule a criatividade, a autonomia em buscar. $\mathrm{O}$ fazer em outra relação com o saber.

O texto "Mudança para nova cidade: comparando as percepções da Casa de Memória Camarolli e a dos moradores de Itá" nos mostra que são possíveis outros movimentos na escola que não apenas as repetições através da cópia, que desconsideram o dizer de outra forma; que se pode avançar no espaço existente entre o que se diz e o que não foi dito, que o sujeito (o estudante pesquisador) pode encontrar espaços para se expressar na permanente tensão entre a paráfrase e a polissemia; que os sentidos sempre podem ser outros.

Os pesquisadores, através do material simbólico construído, iniciam o texto direcionando o leitor para o que querem refletir. Sem meias palavras, vão direto ao objetivo proposto em seu projeto. Rapidamente, procuram contextualizar a problemática que pretendem analisar, informando sobre como as questões do local estão inseridas em uma conjuntura nacional e global, ou seja, um projeto de geração de energia elétrica, tendo como ação a construção de usinas hidrelétricas.

Indicam no texto que houve a necessidade de fazer perguntas para viabilizar a pesquisa. As percepções da população entrevistada e as que circulam na Casa de Memória em torno da

\footnotetext{
${ }^{11}$ Funcionário da Casa de Memória em entrevista concedida aos estudantes em 18 de maio de 2012.
} 
construção da Usina Hidrelétrica Itá e o consequente reflexo sobre a vida dos moradores de uma cidade são o foco investigativo. Explicitam as entrevistas como recurso metodológico.

Entre os discursos dos entrevistados e os articulados no/pelo museu, encontram-se outros discursos. Às vezes, avançam na reflexão, em outras, parece não saberem como continuar. Param. Tecem lacunas. Teriam esses estudantes consciência desse processo? Não sabemos ao certo, porém, temos a convicção de que estão aprendendo a escrever, ler e se posicionar no/ sobre o mundo de outro modo.

O exercício da Iniciação Científica na perspectiva apontada procura ir nessa direção, ou seja, proporcionar ao estudante uma postura que lhe permita não ter um papel tão ingênuo na compreensão dos fenômenos naturais e sociais e suas inter-relações e, por conseguinte, não considerar com naturalidade determinadas situações que envolvam sociedade, ciência e tecnologia em seus cotidianos. Nesse pensar, compreendemos que uma "iniciação" aos assuntos das ciências e das tecnologias em contextos escolares pode assumir significativo papel crítico-emancipador. Ao procurar superar uma compreensão tradicional que apresenta tais processos de produção de conhecimento como "resultado de genialidades de um indivíduo" (AVELLANEDA; LINSINGEN, 2014, p. 517), a IC pode possibilitar o fortalecimento de relações com o saber que contribuam para a produção de outros sentidos sobre o papel formativo da escola, distanciando-se, portanto, de uma perspectiva de educação bancária (FREIRE, 2005) ainda muito frequente nas escolas brasileiras.

Consideramos que o texto apresentado pelos estudantes é marcado pela função-autor. Ao produzir discursos, os sujeitos retomam “já ditos”, inscrevem-se no que Orlandi (2005) denomina de repetições. Assim, foi possível perceber uma forte presença da repetição histórica, aquela em que o conhecimento adquirido pelos estudantes, na perspectiva da autoria, torna-se mais evidente em função de que conseguem produzir discursos interpretáveis, situados historicamente. Nos gestos de autoria, identificamos os sujeitos em constante processo de interação com diferentes informações, interpretando e materializando discursivamente novas compreensões, ou seja, "não necessariamente decodificando ou apreendendo o sentido" (LINSINGEN; CASSIANI, 2010, p. 167) dado pelos textos lidos e ambientes visitados.

Por fim, retomando a epígrafe deste texto e considerando a experiência com IC, bem como a análise das produções dos estudantes pesquisadores, podemos inferir sobre o fecundo potencial da escola enquanto espaço dialógico e de autoria em torno do debate que privilegie temáticas sociotécnicas. É papel da escola e de seus coletivos o pensar sobre outras relações com o saber, exercício necessário para tentarmos explorar outros sentidos sobre o ser/fazer escolar. Nesse sentido, destacamos a necessidade de ampliação dos espaços curriculares de discussões CTS em contextos escolares. A tentativa de um maior envolvimento de diferentes campos do conhecimento, pode contribuir para estimular o que tal perspectiva tem de mais fecundo em sua essência: possibilitar encontros interdisciplinares e assim contribuir para, como afirma Santos (1996), formar pessoas capazes de se posicionar corretamente no mundo. 


\section{Referências}

AVELLANEDA, M. F.; LINSINGEN, I. v. Um olhar para a educação científica e tecnológica a partir dos estudos sociais da ciência e da tecnologia: abrindo novas janelas para a educação. In: KREIMER, P. et al. (Coord.). Perspectivas latinoamericanas en el estudio social de la ciencia, la tecnología y la sociedad. México: Siglo XXI, 2014. p. 505-518.

BUENO, J.; RAMOS, L.; SANTOS, L. Projeto de pesquisa: mudança para nova cidade. Florianópolis: UFSC: Colégio de Aplicação, 2012a. (Texto não publicado).

. Ensaio escolar: mudança para nova cidade: comparando as percepções da Casa de Memória Camarolli e a dos moradores de Itá. Florianópolis: UFSC: Colégio de Aplicação, 2012b. (Texto não publicado).

CHARLOT, B. Da relação com o saber: elementos para uma teoria. Porto Alegre: Artmed, 2000.

\section{CONSELHO NACIONAL DE DESENVOLVIMENTO CIENTÍFICO E} TECNOLÓGICO. Bolsas por quotas no país: RN-017/2006. Brasília, 2006. Disponível em: <https://tinyurl.com/y9nf78re>. Acesso em: 19 jan. 2018.

Bolsas por quota no país (ICJ-alterações): RN-027/2008. Brasília, 2008.

Disponível em: <https://tinyurl.com/y8cymenn>. Acesso em: 19 jan. 2018.

FREIRE, P. Extensão ou comunicação? 13. ed. Rio de Janeiro: Paz e Terra, 1977.

. Pedagogia do oprimido. 31. ed. Rio de Janeiro: Paz e Terra, 2005.

GIRALDI, P. M. Leitura e escrita no ensino de ciências: espaços para produção de autoria. 2010. 350 f. Tese (Doutorado em Educação Científica e Tecnológica) - Universidade Federal de Santa Catarina, Florianópolis, 2010.

KREIMER, R. História del mérito. 2000. Disponível em: < https://www.filosofiaparalavida. com.ar/Historia_del_merito_libro.pdf >. Acesso em: 16 dez. 2016.

LINSINGEN, I. Perspectiva educacional CTS: aspectos de um campo em consolidação na América Latina. Ciência \& Ensino, Piracicaba, v. 1, número especial, 2007. Disponível em: <http://prc.ifsp.edu.br/ojs/index.php/cienciaeensino>. Acesso em: 12 out. 2016.

LINSINGEN, I.; CASSIANI, S. Educação CTS em perspectiva discursiva: contribuição dos estudos sociais da ciência e da tecnologia. Redes, Buenos Aires, v. 16, n. 31, p. 163-182, 2010. Disponível em: <http://www.redalyc.org/articulo.oa?id=90721346008>. Acesso em: 19 jan. 2018.

MAPA interativo de Santa Catarina. Disponível em: < http://www.mapainterativo.ciasc.gov. br/pontoaponto.phtml>. Acesso em: 18 jan. 2018.

ORLANDI, E. Análise de discurso: princípios e procedimentos. Campinas: Pontes, 2005.

Autoria, leitura e efeitos do trabalho simbólico. Campinas: Pontes, 2012.

PÊCHEUX, M. Semântica e discurso: uma crítica à afirmação do óbvio. Campinas: Ed. da Unicamp, 1988. 
PORTO-GONÇALVES, C. W. A globalização da natureza e a natureza da globalização. Rio de Janeiro: Civilização Brasileira, 2015.

SANTOS, M. O espaço do cidadão. 4. ed. São Paulo: Nobel, 1998.

. Técnica, espaço, tempo: globalização e meio técnico-científico-informacional. São Paulo: Hucitec, 1996.

TROTT, T. M. C. Produção textual escrita: ensaio escolar. In: PÉ na estrada do conhecimento: iniciação científica na escola. Florianópolis, 10 jul. 2008. Disponível em: $<$ http://pesnaestradadoconhecimento.blogspot.com.br/2008/07/produo-textual-escritaensaio-escolar.html>. Acesso em: 19 fev. 2016.

UNIVERSIDADE FEDERAL DE SANTA CATARINA. Colégio de Aplicação. Relatório "Pés na estrada do conhecimento: iniciação científica na escola". Florianópolis, 2012.

VYGOTSKY, L. S. Pensamento e linguagem. São Paulo: Martins Fontes, 1988. 